\title{
A tool for assessing the horizontal dribble and jumping throw in young handball players
}

\author{
FERNANDO G. SANTOS 1 | JOSÉ A. R. MAIA² | EDUARDO E. GUIMARÃES² | MATHEUS M. PACHECO | JOSÉ A. \\ SILVA² | GO TANI ${ }^{1}$
}

1 School of Physical Education and Sport, University of São Paulo (USP), São Paulo, SP, Brazil.

${ }^{2}$ CIFI2D, Faculty of Sport, University of Porto, Porto, Portugal.

${ }^{3}$ Katholieke Universiteit Leuven, Leuven, Belgium.

Correspondence to: Fernando Garbeloto dos Santos. School of Physical Education and Sport, University of São Paulo. Professor Mello Moraes 65, São Paulo, Brazil. email: fegarbeloto@gmail.com

https://doi.org/10.20338/bjmb.v15i3.242

\begin{abstract}
HIGHLIGHTS
- The checklist demonstrated sufficiently reliable assessments of the dribbling with a horizontal jumping throw.

- The checklist can be used by raters with different levels of experience.

- The checklist is a simple and reliable way to assess dribbling with a horizontal jumping throw.
\end{abstract}

\section{ABBREVIATIONS}

C1 to $\mathrm{C} 15$ Individual components

FMS Fundamental movement skills

ICC Intraclass correlation coefficient

$K \quad$ Cohen's $K$

P33, P66 and P99 Performance percentiles

\section{PUBLICATION DATA}

Received 30042021

Accepted 20072021

Published 01092021
BACKGROUND: Validated tests for the quality of movement patterns are important to help teachers to assess and induce positive performance changes. However, few tests are available for handball sport skills.

AIM: Therefore, we developed and validated a checklist to assess dribbling with a jumping throw.

METHOD: First, three handball experts were invited to verify if the checklist which contained all the components that describe the skills, and the logical validity process. Then, fifty participants, aged $8-12$ years old, performed the skill of dribbling with a horizontal jumping throw, fifteen of them were re-tested one week apart. Two raters were also selected to conduct an intra- and inter-rater objectivity assessment. McNemar tests were used to compare the proportion of proficient and non-proficient performance between raters. Cohen's $\mathrm{k}$ tests were used to test the intra and inter-rater objectivity. The intra-class correlation coefficient was used to estimated reliability (test-retest).

RESULTS: The results confirmed that the checklist contained the necessary criteria to characterize the skill and to discriminate children with different proficiency levels. Moderate-to-high inter-and intra-rater agreements were found. Children's performance pre and post-test were highly reliable.

CONCLUSION: In conclusion, the proposed checklist can reliably analyze the movement pattern of the dribbling with horizontal jumping throw - which can be highly useful for teachers and sports coaches.

KEYWORDS: Sport skills | Motor performance | Motor development | Team sport games

\section{INTRODUCTION}

It is acknowledged that successful performance in team-handball is dependent on a complex network of factors, namely, players' body size and composition, motor coordination, technical and tactical skills, physical fitness as well as other contextual and social factors.1,2 Despite its popularity, and the growing number of scientific reports on the topic, handball studies remain scarce. Consequently, the number of studies addressing the development of new tools or tests for specific team-handball motor skills can be considered rare. ${ }^{1}$

Although there is an agreement as to the importance of adequate assessment tools in the teaching-learning process, ${ }^{3}$ most tests available in team sports are directed towards general physical capabilities (e.g., lower limb strength, physical fitness) detached from the context of the game.4,5 Further, the majority of tests specific to team-handball mostly assess players' physical performance ${ }^{6,7}$ disregarding other essential aspects of the sport. One essential aspect is the assessment of the movement patterns of the core skills of the game, such as the dribbling with a horizontal jumping throw, which is the topic of this paper. 
Dribbling, jumping, and throwing are directly associated with players' performance ${ }^{8,9}$ and have been used in the detection of team-handball talented players. ${ }^{10}$ Currently, however, these complex skills are assessed based on either their outcome effects (e.g., dribbling velocity, throwing precision) or highly technical biomechanical analyses. ${ }^{11,12}$ The former is overly simplistic for identifying component skills that must be improved and/or corrected, while the latter requires specific hard-to-access equipment.

The skill of dribbling with a horizontal jumping throw occurs in a combined sequence of the aforementioned skills when attempting to score at the game. There is no doubt that a proper combination of these skills requires not only systematic practice but also accurate instructions from coaches and teachers to guide athletes in their learning. Thus, the availability of tests to properly assess this skill is highly needed to inform coaches and physical education teachers as to which movement aspects need to be improved. ${ }^{8}$ Yet, we are not aware of available tools to assess young students/athletes' proficiency in this complex task. When coaching is adequately focused, improving a single skill component can facilitate the reorganization of the entire movement pattern and affect overall performance..$^{13}$ Thus, in this study we developed and validated an assessment tool, in the form of a checklist, that could be reliably used to assess dribbling with a jumping throw.

\section{METHODS}

To develop the checklist, we followed Safrit and Wood ${ }^{14}$ and Mokkink ${ }^{15}$ guidelines to appraise logical and decision validity, participants' performance reliability, and intra-and inter-rater objectivity. The research protocol project was approved by the University of São Paulo Institutional Review Board (CAAE: 66020517.0.0000.5391).

\section{Participants}

We invited all $3^{\text {rd }}$ to $7^{\text {th }}$-grade students (8-12 years old) enrolled in mandatory, twice-per-week, physical education classes in a private school to take part in this study. Only those whose parents/legal guardians provided signed informed consent were enrolled as participants. Participants with physical and/or intellectual disabilities that could impair their ability to respond to all assessment items were excluded. Following guidelines for a validation process, we recruited fifty students for this study (22 girls; aged $8[n=1], 9[n=$ 12], 10 [ $n=7], 11$ [ $n=24]$, and 12 years old [ $n=6]$ ]) through convenience sampling, and their descriptive data can be found in Table 1. All participants were also involved in a separate longitudinal research project investigating fundamental characteristics of their movement skills development. No participants had previous experience in systematic team-handball practice.

\section{Procedure}

Logical validity

The first step towards the development of the checklist was to verify if it contained all the components that describe the skill and, thus, would form the basis to assess it - a procedure termed as logical validity. ${ }^{14}$ The first derived components were from available team-handball books. $., 16,17$ 
Table 1 - Percentiles of performance (raw score) for boys and girls separated by age groups (Group $1<11$ years old; Group $2>11$ years old).

\begin{tabular}{|c|c|c|c|c|c|c|c|c|c|c|}
\hline & \multicolumn{5}{|c|}{ GROUP 1} & \multicolumn{5}{|c|}{ GROUP 2} \\
\hline & $\begin{array}{l}\text { Median } \\
\text { Age } \\
\text { (SD) }\end{array}$ & Sample (n) & & Tertil & & $\begin{array}{l}\text { Median } \\
\text { Age } \\
\text { (SD) }\end{array}$ & Sample (n) & & Tertil & \\
\hline & & & 33 & 66 & 99 & (SD) & & 33 & 66 & 99 \\
\hline Boys & $9.3(.50)$ & 12 & 9 & 13 & 13 & $11(.48)$ & 16 & 9 & 12.4 & 12.4 \\
\hline Girls & $9.2(.70)$ & 8 & 5 & 7 & 7 & $11(.26)$ & 14 & 7 & 9 & 9 \\
\hline
\end{tabular}

The second step in building the checklist was to invite three specialists, named Expert 1, Expert 2, and Expert 3, that held a University degree in Physical Education with at least, 10 years of team-handball teaching to children and/or adolescents to assess whether the chosen components were sufficient to describe the skill. They assessed the representativeness of the included components of the checklist comprising the skill (dribbling with a jumping throw).

The checklist went through a series of two consecutive versions before a final consensus was reached on the decisive checklist (the third version). The first version was based on team-handball literature and comprised 13 components. This version was sent to the expert panel for adding, changing, or removing any component according to their degree of relevance. From this initial set, two new components were added, and four components were suggested to be revised. We then elaborated a second version of the checklist, which was sent back to the experts so that further changes could be made, if necessary. In this new version, experts suggested small changes, but no components were excluded or added. The three experts carried out the evaluations completely independently.

The final version was sent to the three experts who made a detailed content analysis. The experts agreed that the components established in the third version were sufficient to describe the dribbling with a jumping throw. The final version comprised of 15 qualitative dichotomous criteria (Table 2): observance of criterion $=1$ (score of one), otherwise $=0$ (score of zero), that represent the dribbling with a horizontal jumping throw.

\section{Dribble with horizontal jumping throw}

To perform the dribbling with a horizontal jumping throw test, each participant had to perform one serial skill with three components (e.g., dribble, sequential steps, and horizontal jumping throw) successfully transitioning between them (e.g. from dribble to sequential steps). Participants were instructed to dribble the ball, with their preferred hand, towards the middle of the court (delimited point). Then, they would hold the ball with one hand, execute a maximum of three steps, jump and throw the ball to the goal (see Figure 1). After detailed verbal instruction, the experimenter demonstrated the task. Before starting, participants were instructed to hold a team-handball ball (Team-Handball Ball Penalty $\mathrm{H} 1$ - Children) with the preferred hand facing down for at least 5 seconds. If the participant could not hold the ball, he or she performed the test with a smaller and lighter ball (Rubber Penalty Initiation ball $\mathrm{N}^{\circ} 10$ ). 
Table 2 - Criteria (C) and major errors (ME).

C1 Gallop or run during the dribbling phase.

If the participant walks while dribbling, he/she does not score on this $\mathrm{C} 1$.

$M E$ If the participant does not score on this component, he/she does not score on the $\mathrm{C} 4$

C2 Dribble with the preferred hand without losing ball control.

$M E$ If the participant changes hands, uses both hands, or holds the ball, he/she does not score on C2.

C3 During the dribbling phase, the ball touches the hand at about hip and shoulder height.

$M E$ If the participant contacts the ball below the hip or above the shoulder line, he/she does not score on $\mathrm{C} 3$.

C4 At the end of the dribbling phase and beginning of the steps phase (transition moment), the participant holds the ball with one or both hands and starts the steps continuously.

$M E$ If the participant stops abruptly after the end of the dribbling phase, he/she does not score in C4.

C5 Participant executes between 2 and 3 steps after holding the ball (after the last dribble)

$M E$ If the participant performs only one or more than three steps, he/she does not score on C5.

C6 During the steps phase, the participant holds the ball with the palm of the hand downwards.

$M E$ If the participant holds the ball with the palm facing upwards, he/she does not score on C6.

C7 The participant makes the transition from step to jump continuously (in a harmonic way).

$M E$ If the participant stops the steps abruptly and then executes the jump, he/she does not score on C7.

C8 At the end of the stepping phase, the participant jumps (take-off) with the leg opposite the arm of the throw.

If the participant take-off with the leg corresponding to the throwing arm, he/she does not score

$M E$ on $\mathrm{C} 8$ and $\mathrm{C} 14$.

If the participant's take-off with both legs, he/she does not score on C8.

C9 The leg corresponding to the throwing arm is flexed (knee flexion) and lifted high and to the side during the jump.

$M E$ If the participant flexes both legs, he/she scores on C9.

The participant moves the arm backwards (performing a semicircle or sideways motion of the

C10 hand) placing the ball behind the headline to start the throwing movement during the transition between the steps and the jump.

$M E$ If the participant drives the arm forward and then backwards, he/she does not score on $\mathrm{C} 10$

C11 At the moment before the throw, hip and shoulder rotate
to a point where the non-throwing side faces the goal.

$M E$ If the rotation was not enough to face the opposite shoulder in the direction of the goal, he/she does not score on C11.

C12 Throws the ball to the goal while in suspension.

$M E$ If the participant shoots after touching one or both feet on the ground, he/she does not score on $\mathrm{C} 12$.

C13 After throwing the ball, the arm follows through beyond release (down and across the body)

$M E$ If the participant stops the movement after throwing the ball (parallel to the torso), he/she does not score on C13.

C14 The participant lands with the same leg that made the jump.

$M E$ If the participant lands with the take-off leg or with both legs, he/she does not score on C14.

C15 The participant strikes the ball into the goal.

\begin{tabular}{l|l|l|l|l}
\hline Santos et al. & 2021 & VOL.15 & N.3 & https://doi.org/10.20338/bjmb.v15i32.242
\end{tabular}




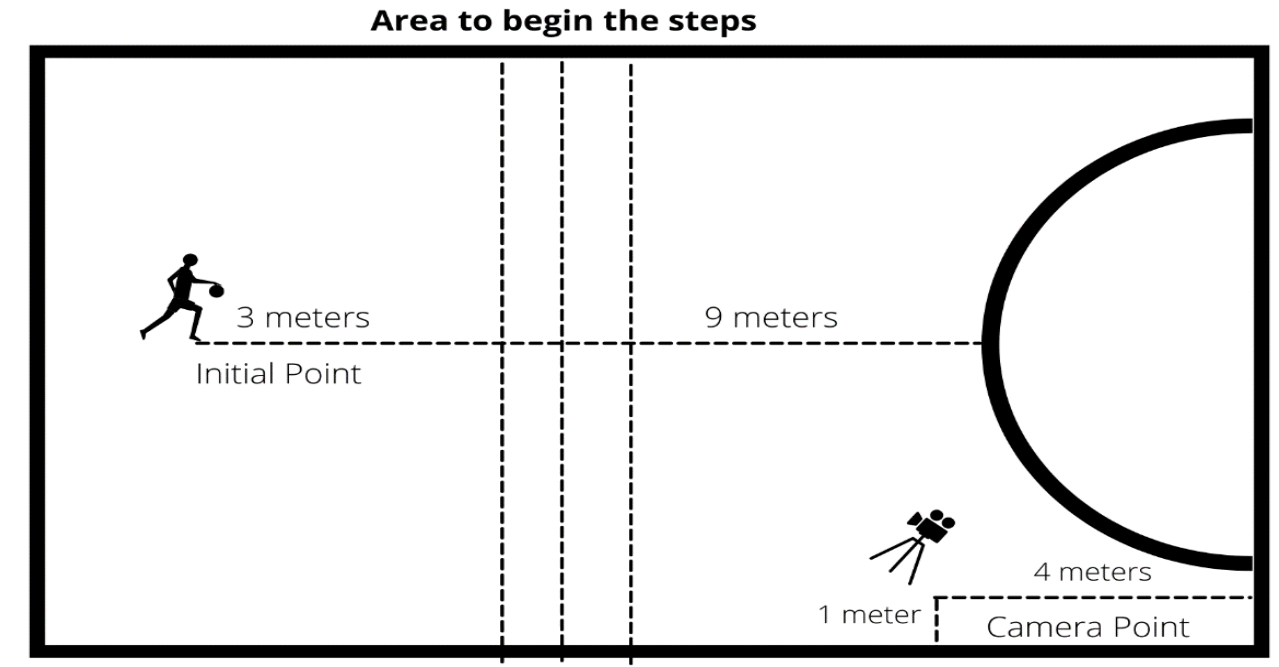

Figure 1. Basic display of the field conditions for assessment.

Once confirmed that the participant clearly understood all the instructions, he/she performed the first trial (familiarization) followed by two new trials recorded for later assessment. If the participant showed no understanding of the task, the investigator demonstrated it once more, and then the child performed the task. All valid trials were recorded using a fixed camera (Sony HDR-PJ540) positioned $4 \mathrm{~m}$ from the end of the court and $1 \mathrm{~m}$ from the sideline (see Figure 1). All videos were analyzed using Kinovea 0.8 software.

\section{Decision validity}

After logical validation, Expert 3 assessed 50 participants' proficiency to verify if the checklist was sensitive enough to identify children with different levels of performance, i.e., proficient and non-proficient, thus concluding the decision validity process. ${ }^{14}$ Expert 3 was the most experienced one; he had the largest record of handball teaching at college level being also a professional team-handball coach. Thus, Expert 3 assessments were considered as the gold standard for further analyses.

\section{Rater objectivity}

After defining the final checklist and creating the gold standard, two raters, designated as Rater 1 and Rater 2, were also selected to conduct an intra-and inter-rater objectivity assessment. Both had a degree in Physical Education, but no experience in team-handball teaching. Rater 1 was the Physical Education teacher of 28 out of the 50 children and had extensive previous experience in fundamental skills' analysis and rating Rater 2 never had any contact with the participants and had no experience in movement analysis.

Objectivity reveals whether different raters would provide the same assessment (inter-rater) and whether the same rater makes the same assessment when rating the same set of videos at different points in time (intra-rater). ${ }^{14}$ To estimate inter-rater objectivity, we compared the assessments made by Expert 3 (gold standard) with those made by Rater 1 and Rater 2 as well as assessments made by Rater 1 versus Rater 2 . Intra-rater objectivity was estimated in assessments made in 30 randomly selected 
children one week apart by Raters 1 and 2. Before starting the analysis, the raters assessed 10 children to clarify potential doubts about the evaluation process. All analyses were done independently between the raters.

\section{Children performance reliability}

Reliability expresses performance consistency within the same examinee when he/she is tested at different points in time (test/retest). To evaluate this, we randomly sampled 15 children (10 boys and 5 girls) aged between 7 to 11 years and retested them one week apart. Both test and retest were done in the same conditions, place, and sets of instructions.

\section{Statistical Analyses}

Performance percentiles (P33, P66, and P99) and the median were calculated from the raw score data (data from Expert 3) to describe boys' and girls' results at different chronological ages (Table 1). In the descriptive data, the participants were separated into two groups, below and above 11 years of age. This separation was performed to represent children with different levels of maturity and motor experience during Physical Education classes.

Intra and inter-rater objectivity between the expert and the two raters (Expert $3 \mathrm{x}$ Rater 1, Expert $3 \times$ Rater 2), and between the two raters (Rater $1 \times$ Rater 2) for each individual component ( $\mathrm{C} 1$ to $\mathrm{C} 15)$ was estimated using Cohen's $\boldsymbol{K}^{14,15}$. For inter-rater objectivity for the sum of the components performed proficiently (raw score ranging from 0 - 15), Cohen's $K$ weighted (linear) was used. The $K$-values were interpreted as weak $(K<$ $0.41)$, moderate $(0.41 \leq \kappa<0.60)$, substantial $(0.60 \leq k<0.81)$, or high $(0.81 \leq k \leq 1.00)$. To compare the proportion of proficient and non-proficient performance in each component assigned by each of the judges (Expert $3 \times$ Rater 1; Expert $3 \times$ Rater 2, and Rater $1 \mathrm{x}$ Rater 2), the McNemar-Browker test was used; further, the percent agreement between and within raters was also calculated. Finally, participants' reliability (test-retest) was estimated within the ANOVA-base framework using the intraclass correlation coefficient (ICC). For reliability, the sum of the components performed with proficiency was used (the raw score that could vary between 0 and 15). This analysis was done to test for possible differences in the mean performance. SPSS 25.0 and MATLAB were used in all analyses, and the significance level was set at $5 \%$.

\section{RESULTS}

\section{Decision validity}

Table 3 reports the proportion of participants classified as proficient by Expert 3 and the two raters in the 15 components. The results of the McNemar test indicate that only in component 10 Rater 1 diverged from Expert 3 ratings. Although divergence was found in a single component, the agreement was found between the results sanctioning its decision validity. 
Table 3 - Relative frequency of children that proficiently performed each component, and McMenar results followed by p-values.

Proficient Proportion $(\% \mathrm{n}=50)$

\begin{tabular}{|c|c|c|c|c|c|c|c|c|c|c|c|c|c|c|c|}
\hline & $\mathrm{C} 1$ & $\mathrm{C} 2$ & $\mathrm{C} 3$ & $\mathrm{C} 4$ & C5 & $\mathrm{C} 6$ & $\mathrm{C7}$ & $\mathrm{C} 8$ & C9 & $\mathrm{C} 10$ & $\mathrm{C} 11$ & $\mathrm{C} 12$ & $\mathrm{C} 13$ & C14 & C15 \\
\hline Exp-3 & 94 & 90 & 92 & 82 & 76 & 76 & 52 & 18 & 54 & 24 & 42 & 70 & 44 & 30 & 96 \\
\hline Rat-1 & 94 & 92 & 94 & 82 & 80 & 84 & 52 & 18 & 50 & 36 & 44 & 70 & 46 & 30 & 96 \\
\hline \multirow[t]{2}{*}{ Rat-2 } & 94 & 96 & 96 & 82 & 80 & 84 & 52 & 26 & 42 & 24 & 50 & 64 & 40 & 26 & 96 \\
\hline & \multicolumn{15}{|c|}{$\chi^{2}(p$ value $)$} \\
\hline $\begin{array}{l}\text { Rat -1 } \\
\text { versus } \\
\text { Exp-3 }\end{array}$ & $\begin{array}{c}.00 \\
(1.0)\end{array}$ & $\begin{array}{c}.00 \\
(1.0)\end{array}$ & $\begin{array}{c}.00 \\
(1.0)\end{array}$ & $\begin{array}{c}.00 \\
(1.0)\end{array}$ & $\begin{array}{c}.50 \\
(.50)\end{array}$ & $\begin{array}{c}2.2 \\
(.12)\end{array}$ & $\begin{array}{c}.00 \\
(1.0)\end{array}$ & $\begin{array}{c}.00 \\
(1.0)\end{array}$ & $\begin{array}{c}.50 \\
(.50)\end{array}$ & $\begin{array}{c}4.1 \\
(.04)^{*}\end{array}$ & $\begin{array}{c}.00 \\
(1.0)\end{array}$ & $\begin{array}{c}.00 \\
(1.0)\end{array}$ & $\begin{array}{c}.00 \\
(1.0)\end{array}$ & $\begin{array}{c}.00 \\
(1.0)\end{array}$ & $\begin{array}{c}.00 \\
(1.0)\end{array}$ \\
\hline $\begin{array}{l}\text { Rat -2 } \\
\text { versus } \\
\text { Exp-3 }\end{array}$ & $\begin{array}{c}.00 \\
(1.0)\end{array}$ & $\begin{array}{c}1.3 \\
(.25)\end{array}$ & $\begin{array}{c}.50 \\
(.50)\end{array}$ & $\begin{array}{c}.00 \\
(1.0)\end{array}$ & $\begin{array}{c}.25 \\
(.62)\end{array}$ & $\begin{array}{c}1.5 \\
(.21)\end{array}$ & $\begin{array}{c}.00 \\
(1.0)\end{array}$ & $\begin{array}{c}2.2 \\
(.12)\end{array}$ & $\begin{array}{c}3.1 \\
(.08)\end{array}$ & $\begin{array}{c}.00 \\
(1.0)\end{array}$ & $\begin{array}{c}1.1 \\
(.29)\end{array}$ & $\begin{array}{c}.80 \\
(.37)\end{array}$ & $\begin{array}{c}.10 \\
(.75)\end{array}$ & $\begin{array}{c}.25 \\
(.62)\end{array}$ & $\begin{array}{c}.00 \\
(1.0)\end{array}$ \\
\hline $\begin{array}{l}\text { Rat }-1 \\
\text { versus } \\
\text { Rat-2 }\end{array}$ & $\begin{array}{c}.00 \\
(1.0)\end{array}$ & $\begin{array}{c}.50 \\
(.50)\end{array}$ & $\begin{array}{c}.00 \\
(1.0)\end{array}$ & $\begin{array}{c}.00 \\
(1.0)\end{array}$ & $\begin{array}{c}.00 \\
(1.0)\end{array}$ & $\begin{array}{c}.00 \\
(1.0)\end{array}$ & $\begin{array}{c}.00 \\
(1.0)\end{array}$ & $\begin{array}{l}2.2 \\
(.12)\end{array}$ & $\begin{array}{c}1.5 \\
(.21)\end{array}$ & $\begin{array}{c}3.1 \\
(.07)\end{array}$ & $\begin{array}{c}.57 \\
(.45)\end{array}$ & $\begin{array}{c}.80 \\
(.37)\end{array}$ & $\begin{array}{c}.80 \\
(.37)\end{array}$ & $\begin{array}{c}.25 \\
(.62)\end{array}$ & $\begin{array}{c}.00 \\
(1.0)\end{array}$ \\
\hline
\end{tabular}

Notes - Exp - 3 = Expert 3; Rat -1 = Rater 1; Rat-2 = Rater 2; $\chi^{2}=$ McNemar test, (p-values); ( $\left.{ }^{*}\right)$ significant p-value.

\section{Objectivity and reliability}

Cohen's $K$ for each component showed moderate-to-high degree of agreement in inter-and intra-rater assessments ranging from $K=0.54$ to $K=1.0$, and from $K=0.44$ to $K$ $=1.0$, respectively (Table 4). Cohen's $K$ weighted for the sum of proficient components showed high agreement between Expert 3 and Rater $1(\kappa=0.73, p<.001)$, Expert 3 and Rater $2(k=0.77, p<.001)$ and Rater 1 and Rater $2(k=0.78, p<.001)$. There was one specific case in the intra-rater assessments (Rater 2 in $C 2$ ) where $k$ was not estimated because only $4 \%$ of participants were classified as non-proficient in this criterion.

The ICC values suggested high reliability in children performance between moment 1 and 2 (ICC = 0.92; $\left.\mathrm{Cl}_{95 \%}=[0.82,0.98], p<.001\right)$. The mean sum of proficient components (raw score) considering boys and girls were $8.67( \pm 0.4)$ in moment 1 , and 8.9 $( \pm 3.1)$ in moment 2. 
Table 4 - Inter- and intra-objectivity k-values (standard-errors).

\begin{tabular}{|c|c|c|c|c|c|}
\hline Criteria & $\begin{array}{c}\text { Expert } 3 \\
\text { versus } \\
\text { Rater-1 }\end{array}$ & $\begin{array}{c}\text { Expert } 3 \\
\text { versus } \\
\text { Rater-2 }\end{array}$ & $\begin{array}{l}\text { Rater-1 } \\
\text { versus } \\
\text { Rater-2 }\end{array}$ & $\begin{array}{c}\text { Rater-1 } \\
\text { versus } \\
\text { Rater-1 }\end{array}$ & $\begin{array}{c}\text { Rater-2 } \\
\text { versus } \\
\text { Rater-2 }\end{array}$ \\
\hline & \multicolumn{5}{|c|}{ Kappa (Standard Error) } \\
\hline C1 & $1.00(.00)$ & $1.00(.00)$ & $1.00(.00)$ & $1.00(.00)$ & $1.00(.00)$ \\
\hline $\mathrm{C} 2$ & $.87(.12)$ & $.54(.22)$ & $.64(.22)$ & $1.00(.00)$ & $.00(.00)^{\mathrm{ns}}$ \\
\hline C3 & $.54(.23)$ & $.64(.22)$ & $.79(.20)$ & $1.00(.00)$ & $.65(.00)$ \\
\hline C4 & $1.00(.00)$ & $.86(.09)$ & $.86(.09)$ & $.90(.10)$ & $.79(.13)$ \\
\hline C5 & $.88(.08)$ & $.77(.11)$ & $.87(.08)$ & $.59(.18)$ & $.85(.12)$ \\
\hline C6 & $.75(.11)$ & $.63(.13)$ & $.70(.14)$ & $.89(.10)$ & $.89(.11)$ \\
\hline $\mathrm{C} 7$ & $1.00(.00)$ & $.92(.06)$ & $.92(.05)$ & $.93(.06)$ & $1.00(.00)$ \\
\hline C8 & $1.00(.00)$ & $.77(.10)$ & $.76(.10)$ & $.89(.11)$ & $.91(.09)$ \\
\hline C9 & $.92(.05)$ & $.69(.10)$ & $.76(.09)$ & $1.00(.00)$ & $.92(.07)$ \\
\hline C10 & $.72(.10)$ & $.78(.10)$ & $.62(.11)$ & $.65(.00)$ & $.44(.16)$ \\
\hline C11 & $.95(.04)$ & $.68(.10)$ & $.72(.09)$ & $.86(.09)$ & $.66(.00)$ \\
\hline $\mathrm{C} 12$ & $1.00(.00)$ & $.77(.09)$ & $.77(.09)$ & $.91(.09)$ & $.78(.11)$ \\
\hline $\mathrm{C} 13$ & $.80(.08)$ & $.60(.11)$ & $.80(.08)$ & $.80(.11)$ & $.79(.11)$ \\
\hline C14 & $1.00(.00)$ & $.80(.09)$ & $.80(.09)$ & $.92(.07)$ & $.92(.08)$ \\
\hline $\mathrm{C} 15$ & $1.00(.00)$ & $1.00(.00)$ & $1.00(.00)$ & $1.00(.00)$ & $1.00(.00)$ \\
\hline
\end{tabular}

\section{DISCUSSION}

The present manuscript developed and validated a checklist to evaluate the dribbling with horizontal jumping throw skill (handball). In general, our results indicate that the checklist developedis valid and reliable for the assessment of dribbling with a horizontal jumping throw in young team-handball players.

Notwithstanding the existence of tools to assess physical fitness components like agility, strength, and flexibility in handball, $4,6,18$ it has been questioned, for example, if these were sensitive enough to explain differences in game performance independently of the level and the age of athletes. ${ }^{19}$ Further, it is now well-acknowledged that other performance characteristics need careful attention and assessment: proficiency in executing handball skills is of utmost importance. To the best of our knowledge, validated 
tools to assess the quality which team-handball motor skills are performed are almost non-existent. ${ }^{4}$ This has been recently emphasized, especially regarding the amount of information that is relevant for intervention planning by the coaching staff. ${ }^{10}$

According to the analysis carried out by the expert panel (logical validation results), the checklist covers the required components to capture the dribble with a horizontal jump throw fundamental aspects. Also, the assessments carried out by Expert 3 and the two raters indicated that the checklist is sensitive to differentiate proficient and non-proficient participants in each of the fifteen components evaluated. Further, raters with different levels of experience in handball were able to differentiate proficient from non-proficient subject's performance, independently of their familiarity with the participants.

Despite the large inter-and intra-rater agreement, two issues need to be discussed. First, McNemar's exact tests showed that there was a difference in the proportions of responses on proficiency between Rater 1 and Expert 3 in component 10 (Table 3). Second, we could not estimate intra-rater agreement for criteria 2 (C2) for Rater 2 (Table 4). For the first case, although the proportion of agreement between Expert 3 and Rater 1 was high (88\% of agreement), and the agreement values between Expert 3 and Rater 2 expressed by Cohen's $K$ were substantial, it might be necessary to give greater attention to component 10 during the training of the application of the checklist. For the second case, a possible explanation might be that the proportion of non-proficient children in this criterion in our sample was only $10 \%$ (see Table 3 ). The lack of variation in performance combined with the small sample size for the analysis could have biased the statistics to provide the intra-rater result for component 2. Alternatively, if we rely on the percentage of agreement, ${ }^{20}$ then a good agreement is evident in all criteria, including $\mathrm{C} 10$ (88\% of agreement) and C2 (92\% of agreement).

Children test-retest reliability showed that no significant changes were noticed in their performance a week apart from the first assessment, i.e., components did not change from proficient to non-proficient or vice versa in a period in which systematic practice did not occur. Similar results with samples and time intervals analogous to ours were found in other sports. ${ }^{21,22}$ In sum, these results show not only that children's performance is consistent, but also that outcome measures were not influenced by putative factors like familiarization or fatigue between trials.

Relative to the performance presented by the participants, some results should be highlighted. Considering all participants, the age range of our sample, from 8 to 12 years, we found substantial proficiency variability between criteria. The criteria C8, C10, and C14 were the components with the lowest frequency of children showing proficiency $(18,24$, and $30 \%$, respectively) with $\mathrm{C} 1, \mathrm{C} 3$, and $\mathrm{C} 15$ presenting the highest frequency $(94,92$, and $96 \%$ ). The added value of the present checklist is exactly the possibility to identify aspects of the movement that must be learned for a given individual allowing coaches to formulate appropriate interventions. It is worth mentioning that due to the interaction between the components of the skill under scrutiny in this article, the improvement of a single component can lead to the reorganization of the entire skill, causing the subject to improve his performance level. ${ }^{13}$

The checklist can also shed light on how movement pattern components are acquired during the learning process, allowing for theoretical interpretations on the acquisition of complex (sport-specific) motor skills. Besides, individuals that did not achieve a given level of proficiency in the fundamental movement skills (FMS) would show 
poor performance in sport-specific skills, ${ }^{23}$ a phenomenon known as the proficiency barrier. ${ }^{24}$ By involving the combination of some FMS (e.g., jumping and throwing), this checklist will also allow investigating the relationship between performance levels in a set of FMS with a sport-specific skill performance, thus allowing to investigate the proficiency barrier.

Although the test may prove to be an important checklist that facilitates the teaching-learning process, some limitations must be highlighted. The first one refers to the number of participants who took the retest. Unfortunately, during the retest period, participants were in a period of formal examination at the school, which limited their free time and space for data collection. However, other studies that validated sporting tools used similar sample sizes and were also able to report good levels of reliability.21,24 In any case, the performance on the test did not appear to be influenced by the small sample size. A second limitation refers to the fact that we did not investigate if the checklist is sensitive enough to detect changes in performance when subjects are involved in intervention programs, the responsiveness of the test. Although we have not assessed the responsiveness, data in Table 1 showed that older children, who had the greatest amount of handball-related motor experiences, tend to outperform their younger peers. This suggests a minimum degree of responsiveness in the test.

The last limitation refers to the feasibility, being a common problem in tests that assess the quality of movement. ${ }^{3}$ In our study, Expert 2 reported that recording the test before the actual analysis could limit the use of the checklist. Yet, this situation is a necessary trade-off between test feasibility and objectivity. That is, video analyses (and current software tools) show higher values of intra-and inter-rater objectivity because they allow the evaluator to review the movement as many times as necessary, increasing the chances of detecting less prominent errors. Removing video-based aspects of the analyses would decrease the objectivity of the tool. Nevertheless, with more experience, raters spent around five minutes per child which decreases the burden of recording the skills for later analyses.

Even with the limitations, to the best of our knowledge, this checklist is probably the first to assess the patterns of movement in dribbling with a horizontal jumping throw in young individuals. In addition to being considered feasible by the experts' panel, our checklist does not require the purchase of any specific material which makes the test inexpensive and applicable in different contexts. Besides, this checklist is highly relevant not only because this technique in sports is representative of high-performance levels, but also as a proper mean for coaches and physical education teachers to assess teamhandball-specific skills. This checklist can also be further applied to understand motor development processes beyond team-handball, i.e., skill acquisition in motor development.

\section{CONCLUSION}

Based on the present results, we conclude that the present checklist can be used by teachers and coaches with different levels of experience, independently of their familiarity with the individuals being assessed. The checklist demonstrated sufficiently reliable assessments of the dribbling with a horizontal jumping throw - a core skill of team handball. 


\section{REFERENCES}

1. Saavedra JM. Handball Research: State of the Art. J Hum Kinet. 2018;63(1):5-8. 10.2478/hukin-2018-0001

2. Haugen TA, Breitschädel F, Seiler S. Sprint Mechanical Properties in Handball and Basketball Players. Int J Sports Physiol Perform. 2019;14(10):1388-94. 10.1123/ijspp.2019-0180

3. Eddy LH, Id LHE, Bingham DD, Crossley KL, Shahid NF, Ellingham-khan M, et al. The validity and reliability of observational assessment tools available to measure fundamental movement skills in school-age children: A systematic review. 2020;(August). 10.1371/journal.pone.0237919

4. Muehlbauer T, Pabst J, Granacher U, Büsch D. Validity of the jump-and-reach test in subelite adolescent handball players. J Strength Cond Res. 2017;31(5):1282-9. 10.1519/JSC.0000000000001607

5. Zapartidis I, Vareltzis I, Gouvali M, Kororos P. Physical Fitness and Anthropometric Characteristics in Different Levels of Young Team Handball Players. Open Sports Sci J. 2009;2(1):22-8. 10.2174/1875399X00902010022

6. Schwesig R, Koke A, Fischer D, Fieseler G, Jungermann P, Delank KS, et al. Validity and reliability of the new handball-specific complex test. J Strength Cond Res. 2016;30(2):47686. 10.1519/JSC.0000000000001061

7. Wagner H, Orwat M, Hinz M, Pfusterschmied J, Bacharach, W D, von Duvillard SP, et al. Testing game-based performance in team-handball. J Strength Cond Res. 2016;30(10):2794-801. 10.1519/JSC.0000000000000580

8. Lidor R, Falk B, Arnon M, Cohen Y, Segal G, Lander Y. Measurement of talent in team handball: the questionable use of motor and physical tests. J Strength Cond Res. 2005;19(2):318-25. 10.1519/1533-4287(2005)19[318:MOTITH]2.0.CO;2

9. Radić N. Handball: From Beginner to Top Player. self-publishing N. Radic; 2013. 199 p.

10. Serrien B, Baeyens JP. Systematic Review and Meta-Analysis on Proximal-to-Distal Sequencing in Team Handball: Prospects for Talent Detection? J Hum Kinet. 2018;63(1):9-21. 10.2478/hukin-2018-0002

11. Wagner H, Pfusterschmied J, Tilp M, Landlinger J, von Duvillard SP, Müller E. Upper-body kinematics in team-handball throw, tennis serve, and volleyball spike. Scand J Med Sci Sport. 2014;24(2):345-54. 10.1111/j.1600-0838.2012.01503.x

12. Skejø SD, Møller M, Bencke J, Sørensen H. Shoulder kinematics and kinetics of team handball throwing: A scoping review. Hum Mov Sci. 2019;64(February):203-12. 10.1016/j.humov.2019.02.006

13. Langendorfer SJ, Roberton MA. Individual pathways in the development of forceful throwing. Res Q Exerc Sport. 2002;73(3):245-56. 10.1080/02701367.2002.10609018

14. Safrit MJ, Wood TM. Introduction to measurement in physical education and exercise science. William C. Brown; 1995. 
15. Mokkink LB, Terwee CB, Patrick DL, Alonso J, Stratford PW, Knol DL, et al. The COSMIN checklist manual. VU Univ Med. 2012;56. 10.1007/s13398-014-0173-7.2

16. Martini K, Prudente A. Andebol: técnica, táctica, metodologia. 1980.

17. Knijnik JD. Handebol: Agôn: o espírito do esporte. São Paulo: Odysseus; 2009.

18. Wagner H, Sperl B, Bell WJ, von Duvillard S. Testing specific physical performance in male team handball players and the relationship to general tests in team sports. J Strength Cond Res. 2019;33(4):1056-64. 10.1519/JSC.0000000000003026

19. Hermassi S, Chelly MS, Wollny R, Hoffmeyer B, Fieseler G, Schulze S, et al. Relationships between the handball-specifc complex test, non-specifc feld tests and the match performance score in elite professional handball players. J Sports Med Phys Fitness. 2018;58(6):778-84. 10.23736/S0022-4707.17.07373-X

20. Grant MJ, Button CM, Snook B. An Evaluation of Interrater Reliability Measures on Binary Tasks Using d-Prime. Appl Psychol Meas. 2017;41(4):264-76. 10.1177/0146621616684584

21. Spasic M, Krolo A, Zenic N, Delextrat A, Sekulic D. Reactive agility performance in handball; development and evaluation of a sport-specific measurement protocol. J Sport Sci Med. 2015;14(3):501-6. PMCID: PMC4541112

22. Pate RR, Freedson PS, Sallis JF, Taylor WC, Sirard J, Trost SG, et al. Compliance with physical activity guidelines: Prevalence in a population of children and youth. Ann Epidemiol. 2002;12(5):303-8. 10.1016/s1047-2797(01)00263-0

23. Clark JE, Metcalfe JS. The mountain of motor development: A metaphor. In: Jane E. Clark $\mathrm{JHH}$, editor. Motor Development: Research and Reviews. NASPE Pulications: Reston; 2002. p. 163-190.

24. Seefeldt V. Developmental motor patterns: implications for elementary school physical education. Psychol Mot Behav Sport. 1979;314-23.

25. Jennings D, Cormack S, Coutts AJ, Boyd L, Aughey RJ. The Validity and Reliability of GPS Units for Measuring Distance in Team Sport Specific Running Patterns Denise. Int J Sports Physiol Perform. 2010;5:328-41. 10.1123/ijspp.5.3.328

Citation: Santos FG, Maia JAR, Guimarães EE, Pacheco MM, Silva JA, Tani G. (2021). A Tool for Assessing the Horizontal Dribble and Jumping Throw in Young Handball Players. BJMB, 15(3): 195-206.

Editors: Dr Fabio Augusto Barbieri - São Paulo State University (UNESP), Bauru, SP, Brazil; Dr José Angelo Barela São Paulo State University (UNESP), Rio Claro, SP, Brazil; Dr Natalia Madalena Rinaldi - Federal University of Espirito Santo (UFES), Vitória, ES, Brazil.

Copyright:@ 2021 Santos, Maia, Guimarães, Pacheco, Silva and Tani and BJMB. This is an open-access article distributed under the terms of the Creative Commons Attribution-Non Commercial-No Derivatives 4.0 International License which permits unrestricted use, distribution, and reproduction in any medium, provided the original author and source are credited.

Funding: There was no funding for this study.

Competing interests: The authors have declared that no competing interests exist.

DOI: https://doi.org/ 0.20338/bjmb.v15i3.242 